J. Bangladesh Acad. Sci., Vol. 42, No. 2, 183-190, 2018

DOI: https://doi.org/10.3329/jbas.v42i2.40050

\title{
MEASUREMENT OF FEEDBACK REACTIVITY EFFECTS OF THE BAEC TRIGA REACTOR
}

\author{
MD. AL AMIN HOSSAIN", MD. ABDUL MALEK SONER ${ }^{3}$, MD. ABDUS SALAM ${ }^{3}$, \\ MD. FAZLUL HUQ ${ }^{2}$, MD. SHAMSUL HUDA SOHEL ${ }^{2}$ \\ Nuclear Power Plant Company Bangladesh Limited (NPCBL), Rooppur, Ishwardi, Pabna, \\ Bangladesh
}

\section{ABSTRACT}

The aim of this study is to measure the feedback reactivity effects of the Bangladesh Atomic Energy Commission (BAEC) TRIGA Research Reactor (BTRR). Using digital instrumentation and control (I\&C) system, feedback parameters such as reactivity coefficients of fuel, moderator and power effects are measured. At $300 \mathrm{~kW}$ reactor power, the obtained results for fuel temperature coefficient are $0.664 \% /{ }^{\circ} \mathrm{C}$ and $0.765 \% /{ }^{\circ} \mathrm{C}$ at $C_{1}$ and $D_{3}$ core positions respectively. The results for $100 \mathrm{~kW}$ to $400 \mathrm{~kW}$ reactor power show its increasing nature as the reactor power increases. The measured value of the moderator temperature coefficient is found to be $0.419 \% /{ }^{\circ} \mathrm{C}$ at $500 \mathrm{~kW}$ reactor power. The power coefficient of reactivity is measured for several power ranges from $50 \mathrm{~kW}$ to $2.5 \mathrm{MW}$ and the average value is found to be $0.0757 \% / \mathrm{kW}$. The measured values of the reactivity coefficients are found to be in a good agreement with the GA Safety Analysis Report (SAR) provided for BTRR.

Keywords: TRIGA reactor, Reactivity, Fuel temperature coefficient, Moderator temperature coefficient, Power coefficient.

\section{INTRODUCTION}

The BAEC TRIGA Research Reactor (BTRR) is a light water cooled and moderated, tank type 3 MW thermal reactor which is used in different fields of science and technology since 1986. BAEC TRIGA reactor fuel is a solid homogeneous mixture of Erbium Uranium Zirconium Hydride (Er-U-ZrH) alloy containing about $20 \%$ by weight of uranium enriched to about $19.7 \%$ U-235 and about $0.47 \%$ by weight of erbium in a cylindrical rod with stainless steel (SS-304) cladding (GA Technologies, 1984). The use of Er-U-ZrH material for the fuelmoderator elements ensures the inherent safety

features and gives the TRIGA core a large negative fuel temperature coefficient (Mesquita and Souza, 2008). As the temperature coefficient is negative, a significant amount of reactivity is required to compensate for the change in temperature (Lee et al. 2009; Mesquita and Souza, 2010). Light water is used as moderator in TRIGA research reactor and it is under moderated resulting a negative moderator temperature coefficient (DOE, 1993). Power coefficient of reactivity is the combined effect of all the parameters influenced by temperature. For TRIGA system, power coefficient is also

\footnotetext{
*Corresponding author: <alamin58.ne@gmail.com>.

${ }^{2}$ Department of Nuclear Engineering, University of Dhaka, Dhaka - 1000, Bangladesh.

${ }^{3}$ Center for Research Reactor (CRR), AERE, Ganakbari, Savar, Dhaka, Bangladesh.
} 
negative because of its large negative fuel temperature coefficient and moderator temperature coefficient (Atomics General, 1967). Reactivity of a reactor core changes inherently with temperature, fuel burn up and core configuration, pressure and poisons (Hussain, 2011). Therefore, it is necessary to investigate the reactivity coefficients with operational time to ensure the operational safety of the reactor. The reactivity coefficients have been measured by various methodologies by various rector facilities (Kostić, 1997; Laggiard, \& Runkel, 1997; Omar et al. 2012; Rahgoshay \& Noori-Kalkhoran, 2013 Safarzadeh et al. 2015). Among them, noise analysis is an interesting way to measure the reactivity coefficients therefore several algorithms have been developed based on noise analysis technique (Shimazu, 1995; Demaziere et al. 2003, Andersson et al. 2003; Mori et al. 2003); Still, noise analysis technique shows some drawbacks because of the biasing nature of the estimated parameters from the true values (Mori, 2004). This paper represents the results of the research conducted to measure the feedback reactivity effects of the BTRR based on a simple methodology using NCCM and FCCM for different power levels.

\section{METHODOLOGY}

The change in reactivity for per degree change in temperature is termed generally as temperature reactivity coefficient (TRC); that is,

$$
\alpha_{x}=\frac{d \rho}{d T_{x}}
$$

where, $d \rho$ is the reactivity compensation due to temperature change, $d T$ is the temperature change and $\alpha_{x}$ is the fuel temperature coefficient (FTC) when fuel temperature is changed and $\alpha_{x}$ is the moderator temperature coefficient (MTC) when moderator temperature is changed (Duderstadt and Hamilton, 1976). Fuel temperature coefficient is measured through the sequential $\mathrm{ON}$ and $\mathrm{OFF}$ of the primary coolant pump. Initially, the reactor is made critical at $100 \mathrm{~kW}$ using all the control rods. Recording all the control rod positions and the fuel temperatures of different fuel channels, the primary coolant pump is then turned $\mathrm{ON}$ to cool the fuel. Due to the decrease of fuel temperature, control rod positions changed that is recorded along with the new fuel temperatures. Fuel temperature change is obtained from the difference of two temperature recorded and the reactivity compensation is calculated using control rod calibration data.

To measure the MTC, reactor is made critical at $500 \mathrm{~kW}$ manually using all the control rods keeping the regulating rod at a desired position and the demand power is set at $500 \mathrm{~kW}$. The operation mode of the reactor is set from manual to automatic and run for about half an hour to allow moderator temperature to increase within the safety limit $\left(43{ }^{\circ} \mathrm{C}\right)$ of the BTRR (GA SAR, 1986). The temperature effect of the moderator is compensated automatically by the regulating control rod to operate the reactor at a constant power. The final temperature of the moderator and position of regulating rod are recorded. The temperature difference of the moderator $d T_{M}$ is determined from the thermocouple reading and the reactivity insertion for the corresponding control rod positions came from the control rod calibration data. Initial and final moderator temperature are found to be $28{ }^{\circ} \mathrm{C}$ and $38{ }^{\circ} \mathrm{C}$ respectively after half an hour operation. The reactor hall temperature was around $29{ }^{\circ} \mathrm{C}$ during the measurement. At the fixed demanding power of $500 \mathrm{~kW}$, the corresponding reactivity and the moderator temp eratures are shown in Table 1. 
Table 1. Regulating rod positions, corresponding reactivity and moderator temperatures at $500 \mathrm{KW}$ critical power.

\begin{tabular}{ccccccc}
\hline $\begin{array}{c}\text { Critical } \\
\text { Power }(\mathbf{k W})\end{array}$ & $\begin{array}{c}\text { Initial rod } \\
\text { position }\end{array}$ & $\begin{array}{c}\text { Final rod } \\
\text { position }\end{array}$ & $\begin{array}{c}\text { Initial } \\
\text { reactivity }\left(\not Z^{\prime}\right)\end{array}$ & $\begin{array}{c}\text { Final } \\
\text { reactivity }\left(\not Z^{\prime}\right)\end{array}$ & $\begin{array}{c}\text { Initial } \\
\text { temp }\end{array}$ & $\begin{array}{c}\text { Final } \\
\text { temp }\end{array}$ \\
\hline $500 \mathrm{~kW}$ & 498 & 508 & 918.318 & 922.512 & $28^{\circ} \mathrm{C}$ & $38^{\circ} \mathrm{C}$ \\
\hline
\end{tabular}

Power coefficient of reactivity relates the change in reactivity when the reactor power is changed per kilo watt, that is,

$\alpha_{p}=\frac{d \rho}{d p}$

where, $d \rho$ indicates the change in reactivity; $d p$ indicates change in reactor power $(\mathrm{kW})$ and $\alpha_{p}$ stands for power coefficient of reactivity (Lewis and Elmer, 2008). Power coefficient of reactivity for various power ranges is calculated by increasing the reactor power (Rabir, 2013). The reactivity compensation along with reactor power is not absolutely linear but it may be considered as linear for smaller power levels
(Souza and Mesquita, 2009, 2011). To determine the reactivity compensation due to power changes, the reactor is made critical manually at $50 \mathrm{~kW}$ under the FCCM inserting 834.008 Clof reactivity. Then the critical power is shifted to $100 \mathrm{~kW}$ manually by all the control rods and the corresponding reactivity insertion is calculated using control rod calibration data. Control rods positions are recorded for several power ranges from $50 \mathrm{~kW}$ to $2.5 \mathrm{MW}$ reactor power and the corresponding reactivity was obtained from reactivity data calculating the power coefficients of reactivity using equation (2). Table 2 . Shows the several power ranges and the corresponding reactivity insertion in cents.

Table 2. Control rod positions and corresponding reactivity for several power levels

\begin{tabular}{|c|c|c|c|c|c|c|c|}
\hline \multirow{2}{*}{$\begin{array}{l}\text { Reactor } \\
\text { Power }\end{array}$} & \multicolumn{6}{|c|}{ Control rod positions } & \multirow{2}{*}{$\begin{array}{c}\text { Reactivity } \\
\text { insertion }(\not \subset)\end{array}$} \\
\hline & Transient & Shim1 & Shim2 & Shim3 & Shim4 & Regulating & \\
\hline $50 \mathrm{~kW}$ & 458 & 457 & 457 & 455 & 456 & 451 & 833.008 \\
\hline $100 \mathrm{~kW}$ & 548 & 457 & 456 & 456 & 454 & 459 & 836.702 \\
\hline $250 \mathrm{~kW}$ & 459 & 462 & 462 & 460 & 456 & 466 & 846.765 \\
\hline $500 \mathrm{~kW}$ & 466 & 468 & 467 & 469 & 467 & 469 & 862.101 \\
\hline $1 \mathrm{MW}$ & 479 & 484 & 486 & 485 & 487 & 489 & 901.796 \\
\hline $1.5 \mathrm{MW}$ & 503 & 503 & 500 & 503 & 505 & 506 & 941.624 \\
\hline $2 \mathrm{MW}$ & 527 & 522 & 526 & 519 & 521 & 530 & 986.186 \\
\hline $2.5 \mathrm{MW}$ & 548 & 547 & 549 & 546 & 545 & 551 & 1035.873 \\
\hline
\end{tabular}

* In Table 2, column 3 represents the control rod positions where, each rod length (15 inch) is represented by 1000 equal units from 0 to 999. 
Updated reactivity data of control rod is essential to measure reactivity feedback parameters because of its changing nature with reactor operation period. Hence, control rod calibration of BTRR was done prior to the measurement of feedback parameters. The effective delayed neutron fraction of BTRR is 0.007 which is a dimensionless quantity (Lamarsh, 1966).

\section{RESULTS AND DISCUSSIONS}

Reactivity worth was measured using positive period method to get the control rod calibration data. The positive period method was used to measure the individual control rod worth and the total reactivity worth obtained for the BTRR control system was $14.75 \$$.

Figs. 1- 2 show the control rod calibration curves of all the six control rods of BAEC TRIGA reactor. From Fig. 1, it is observed that the change of reactivity is maximum at the center region of the core and decreases gradually towards the top and bottom region. This is because the neutron flux is higher at center region than the top and the bottom region (Hosan et al. 2015). It is also observed that worth of the six control rod is different from one another and the maximum worth was found to be $2.804 \$$ for regulating rod and the minimum worth was found to be 1.777 for transient rod.

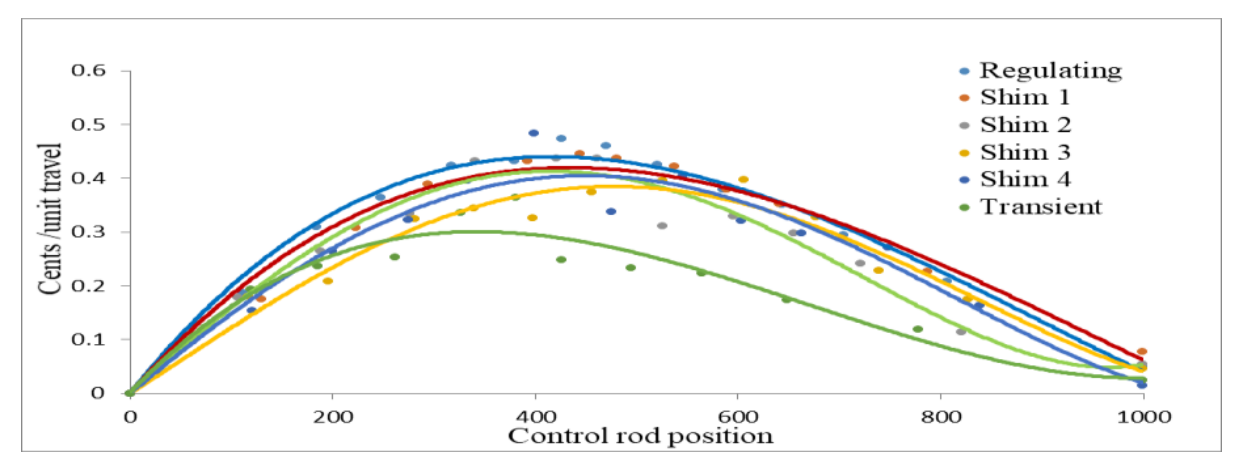

Fig. 1. Differential worth for each unit movement of control rods. The total length (15 inch) of each control rod is divided into 1000 equal units.

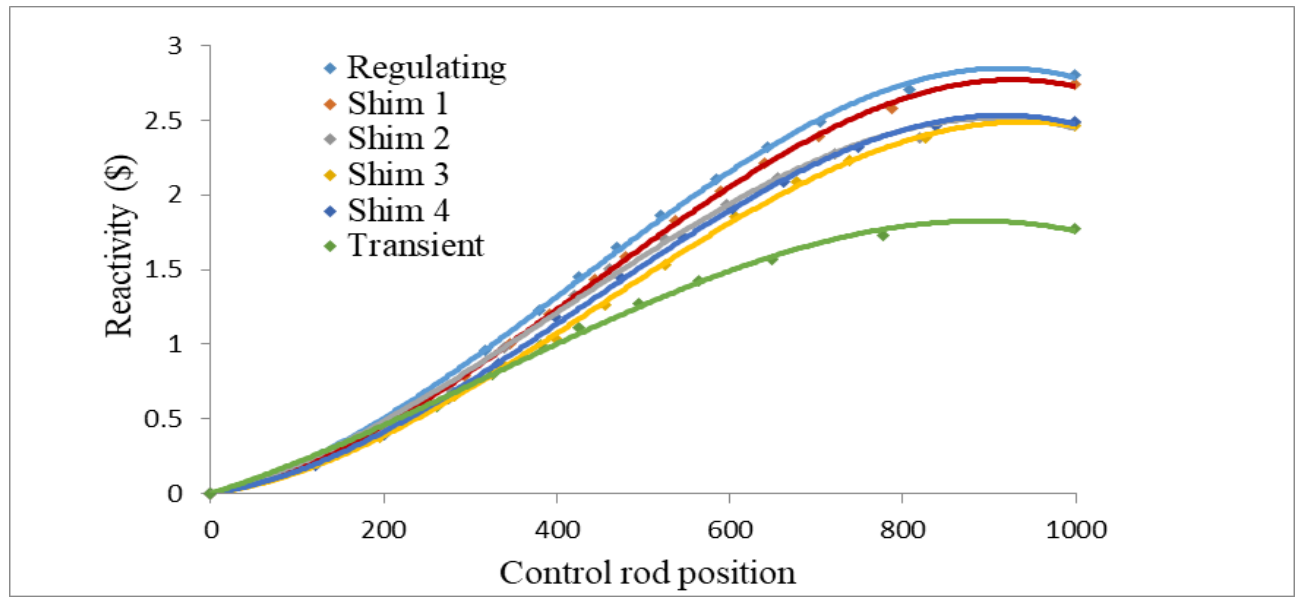

Fig. 2. Integral worth curves of BTRR control rods 
Integral rod worth curves show the change of reactivity variation with the control rod movement. From Fig. 2, it is observed that the slope of each curve is maximum at around half two thermocouples. The results obtained for fuel temperature coefficient at $C_{1}$ and $D_{3}$ positions are $0.664^{\not /} /{ }^{\circ} \mathrm{C}$ and $0.794 \% / \%$ for $300 \mathrm{~kW}$

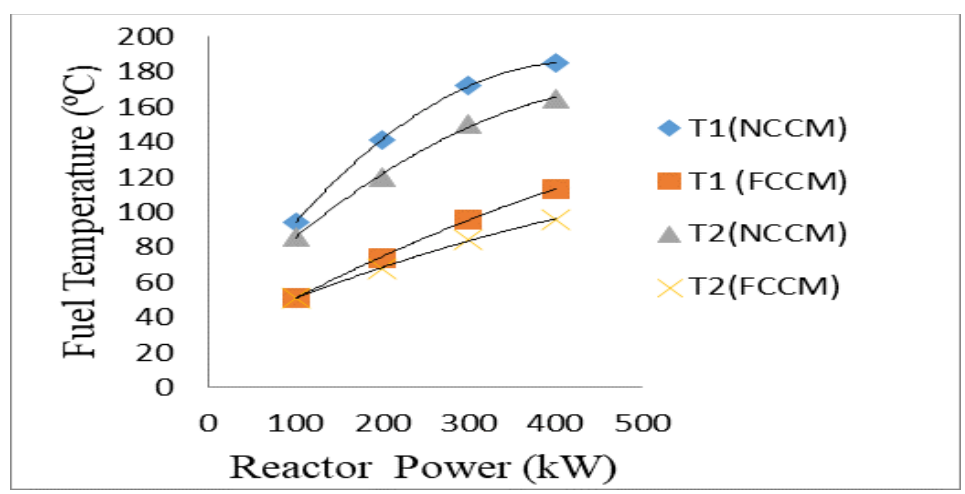

Fig. 3. Fuel temperature change with reactor power

(500) of the whole control rod length (999) as it is expected (Hosan et al, 2015).

Fuel temperature changes when the reactor power changes. FCCM is used to change the fuel temperature sharply. Fig. 3 shows the variation of fuel temperature as the reactor power changes in FCCM and in NCCM. reactor power. For various power levels, it is observed that fuel temperature coefficient increases as the reactor power increases (Fig. 4).

Moderator temperature coefficient was measured at the steady state reactor power at $500 \mathrm{~kW}$ and the obtained result is $0.419^{\not /} /{ }^{\circ} \mathrm{C}$. It is seen that

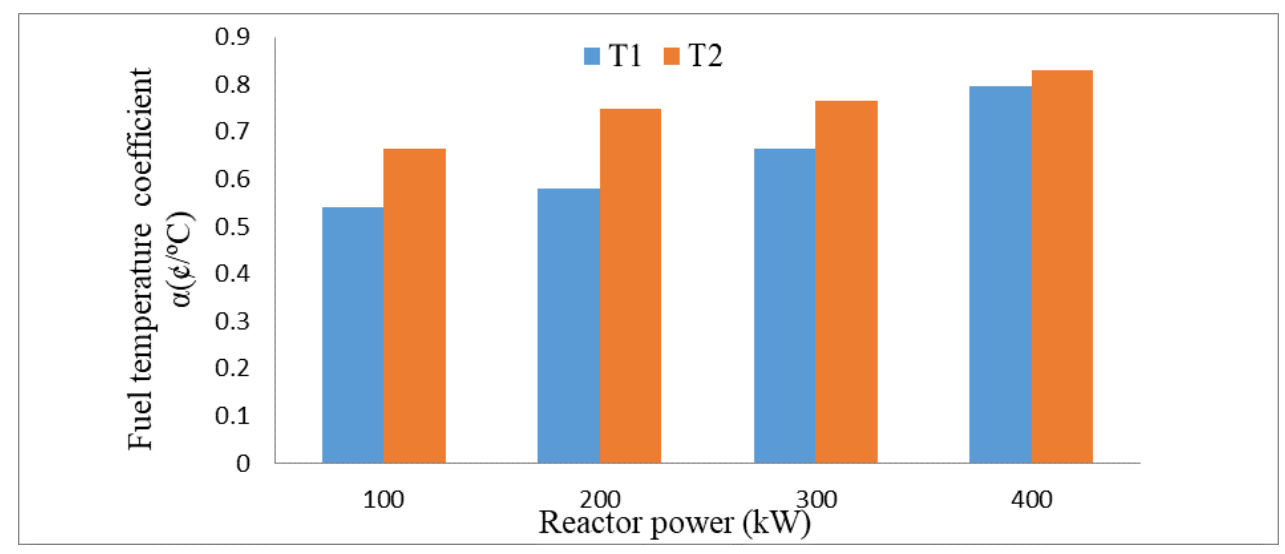

Fig. 4. Fuel temperature coefficient vs reactor power at $C_{1}\left(T_{1}\right)$ and $D_{3}\left(T_{2}\right)$ core locations

Fuel temperature coefficient was measured at two different core locations using two instrumented fuel elements (IFE) embedded with the reactivity coefficient for moderator is smaller than the coefficients for fuel. Fuel elements response almost immediately after any change in 
temperature compared to the moderator (Igor and Matjaz, 2010). For the research reactors, moderator temperature does not change as much as fuel temperature does. But importance must be given to the moderator temperature coefficient for the light water thermal type power reactors (DOE, 1993).

Power coefficient of reactivity for different power ranges is shown in Fig. 5. At $100 \mathrm{~kW}$ reactor power, the power coefficient obtained temperature, fuel burn up and reactor power. Based on the control rod calibration data, fuel temperature coefficient, moderator temperature coefficient and power coefficient of reactivity has been measured using digital instrumentation and control (I\&C) system of BTRR. The average of the results obtained for fuel temperature coefficients at $C_{1}$ and $D_{3}$ positions are $0.654{ }^{\not /} /{ }^{\circ} \mathrm{C}$ and $0.751 \% / \%$ for different reactor



Fig. 5. Variation of power coefficient with reactor power

was $0.0538 \mathrm{\&} / \mathrm{kW}$. As the reactor power increases, the negative feedback of reactivity also increases as a result the power coefficient also increases. Power coefficient was found to be $0.0993 \not / k W$ for $2.5 \mathrm{MW}$ reactor power.

From Fig. 5, it is also observed that, "reactivety must" be inserted if it is desired to make the reactor critical at any higher power level from the previous critical condition

The little discrepancy about the linearity of the power coefficient versus reactor power curve may arise due to the fact that, the power intervals considered in this experiment was not uniform (Table 2).

\section{CONCLUSION}

Evaluation of feedback reactivity effects is very important to understand the reactivity effects on power levels. Moderator temperature coefficient is found to be $0.419^{\not /} /{ }^{\circ} \mathrm{C}$ at $500 \mathrm{~kW}$ reactor power. The average of the power coefficients obtained is $0.0756 \mathrm{k} / \mathrm{kW}$ for $50 \mathrm{~kW}$ to 2.5 MW reactor power range. The precision of the results obtained from the present study depends on the level of accuracy to the measurement of $d \rho, d p$ and $d T$.

\section{ACKNOWLEDGEMENT}

The authors also would like to thank the staff and the reactor operators of the Center for Research Reactor (CRR), Bangladesh Atomic Energy Commission (BAEC) for their help, cooperation and proper guidance. 


\section{REFERENCES}

Andersson, T., Demazière, C., Nagy, A., Sandberg, U., Garis, N. S., \& Pázsit, I. (2003). Development and application of core diagnostics and monitoring for the Ringhals PWRs. Progress in Nuclear Energy, 43(1-4): 35-41.

Atomics, General. 1967. Kinetic behavior of TRIGA reactors. General Atomics Technologies Inc., GA-7882.

Demaziere, C., Pazsit, I., Andersson, T., Severinsson, B., \& Ranman, T. (2003). Analysis of an MTC noise measurement performed in ringhals-2 using gammathermometers and in-core neutron detectors. Progress in Nuclear Energy, 43(14): 57-66.

DOE, 1993. Fundamentals Handbook Nuclear Physics and Reactor Theory Volume 2 of 2, doe-hdbk-1019/2-93.

Duderstadt, J.J.; Hamilton, L.J. Nuclear Reactor Analysis. New York, N.Y.: J. Wiley \& Sons (1976).

GA Technologies, GA_A17054, 1984. TRIGA mark reactor mechanical operation and maintenance manual. In: Prepared for BAEC, Institute of Nuclear Technology Bangladesh, GA project 2299.

General Atomics (GA), 1986. Safety Analysis Report of BAEC 3 MW TRIGA Mark-II Research Reactor.

Hosan M. I., Soner M.A.M., Kabir K. A., Salam M.A. and Huq M.F. 2015. Study on neutronic safety parameters of BAEC TRIGA research reactor. J. Annals of Nucl. Energy, 80: 447-450.

Hussain, A., \& Xinrong, C. (2011). Reactivity feedback calculation of a conceptual TRISO fueled compact PWR core. Progress in Nuclear Energy, 53(1): 76-79.
Igor, L., Matjaz, R., 2010, March. Fuel Temperature Coefficient of Reactivity, Ljubljana.

Kostić, L. (1997). Monitoring of the temperature reactivity coefficient at the PWR nuclear power plant. Annals of Nuclear Energy, 24(1): 55-64.

Laggiard, E., \& Runkel, J. (1997). Evaluation of the moderator temperature coefficient of reactivity in a PWR by means of noise analysis. Annals of Nuclear Energy, 24(5): 411-417.

Lamarsh, J. R. (1966). Introduction to nuclear reactor theory (Vol. 3). Reading, Massachusetts: Addison-Wesley.

Lee, Deokjung, Kord Smith, and Joel Rhodes. 2009 "The impact of U-238 resonance elastic scattering approximations on thermal reactor Doppler reactivity." Annals of Nuclear Energy 36. 3: 274-280.

Lewis, Elmer E. 2008. Fundamentals of nuclear reactor physics. Academic Press, Chapter 9.

Mesquita, Amir Zacarias, and R. M. G. P. Souza. "On-Line Measurement of the Reactivity Temperature Coefficient of the IPR-R1 TRIGA Nuclear Research Reactor." Proceedings of $12^{\text {th }}$ Brazilian Congress of Thermal Engineering and Sciences. 2008.

Mesquita, Amir Zacarias, Souza, Rose Mary Gomes do Prado, 2010. On-line monitoring of the IPR-R1 TRIGA reactor neutronic parameters. J. Prog. Nucl. Energy 52.

Mori, M., Kagami, Y., Kanemoto, S., Enomoto, M., Tamaoki, T., \& Kawamaura, S. (2004). New proposal to void reactivity coefficient estimation method using gray-box model in BWR, (2). Nippon Genshiryoku Gakkai Wabun Ronbunshi, 3(1): 11-23. 
Mori, M., Kaino, M., Kanemoto, S., Enomoto, M., Ebata, S., \& Tsunoyama, S. (2003). Development of advanced core noise monitoring system for BWRS. Progress in Nuclear Energy, 43(1-4): 43-49.

Omar, H., Khattab, K., \& Ghazi, N. (2012). Feedback reactivity coefficients for the Syrian MNSR research reactor. Progress in Nuclear Energy, 54(1), 162-166.

Rabir, Mohamad Hairie, 2013. Measurement of the power and temperature reactivity coefficients of the RTP TRIGA reactor. $J$. Nucl. Eng. and Design, 265: 269-271.

Rahgoshay, M., \& Noori-Kalkhoran, O. (2013). Calculation of control rod worth and temperature reactivity coefficient of fuel and coolant with burn-up changes for VVRS-2MWth nuclear reactor. Nuclear Engineering and Design, 256: 322-331.

Safarzadeh, O., Saadatian-Derakhshandeh, F., \& Shirani, A. S. (2015). Calculation of reactivity coefficients with burn-up changes for VVER-1000 reactor. Progress in Nuclear Energy, 81: 217-227.
Shimazu, Y. (1995). A new method of estimation for moderator temperature coefficient using Fourier transform. Journal of Nuclear Science and Technology, 32(7): 622-628.

Souza, Rose Mary Gomes do Prado, Mesquita, Amir Zacarias, 2009. Measurements of the isothermal, power and temperature reactivity coefficients of the IPR-R1 TRIGA reactor, In: 2009 International Nuclear Atlantic Conference-INAC 2009.

Souza, Rose Mary Gomes do Prado, Mesquita, Amir Zacarias, 2011. Experimental determination of neutronic parameters in the IPR-R1 TRIGA reactor core. In: 2011 International Nuclear Atlantic Conference INAC 2011.

(Received revised manuscript on 9 October 2018) 